\title{
STATUS DAN PERAN MALIOBORO MALL SEBAGAI OBJEK WISATA BELANJA DI KAWASAN MALIOBORO YOGYAKARTA
}

\author{
Muhammad Arief Kurniawan', Endah Tisnawati ${ }^{2}$, Elsa Yuliza ${ }^{3}$ \\ 1,2,3 Program Studi Arsitektur, Fakultas Sains dan Teknologi, Universitas Teknologi Yogyakarta \\ email: arif.kurniawan@uty.ac.id
}

\begin{abstract}
Shopping Mall is a popular shopping tourism now. Malioboro Mall is the only one Shopping Mall in Malioboro Area, a well-known tourist shopping street area for domestic and foreign tourist in Yogyakarta. This research aims to know the status and role of Malioboro Mall as shopping tourism object in Malioboro Area. The method in this research is inductive qualitative. The instruments for collecting the data are documents, questionnaire and interview. The questionnaire is given to the visitor of Malioboro Mall and Malioboro Area to know their perception of Malioboro Mall and Malioboro Area. The interview is done to the management of Malioboro Mall and the resident who lives around the Mall. Status means condition or situation. There is three status of Malioboro Mall, from the architecture, property, and as the shopping tourism object. Architecture status means the reason tourist visit Malioboro Area because the architecture of Malioboro Mall is interesting. Property status means Malioboro Mall just a shopping facility for tourist, status as shopping tourism object means Malioboro Mall become the main destination for tourist in Malioboro Area. Research finding that status as property is dominant than others. The role of Malioboro Mall, is its support, not support or disturb the development of shopping tourism in Malioboro. Research finding Malioboro Mall have a role in support tourism in Malioboro Area, but there is some factor that has to be improved like parking facility in Malioboro Mall and Malioboro Area, the price of product in Malioboro Mall is still expensive and souvenir need more complete, variation and cheap too attract the tourist in Malioboro Mall.
\end{abstract}

Keywords: Malioboro Area, Malioboro Mall, Shopping Mall, Tourism object.

\begin{abstract}
ABSTRAK
Shopping Mall adalah bentuk wisata belanja popular pada saat ini. Malioboro Mall adalah satu-satunya Shopping Mall yang berada di Malioboro, sebuah kawasan wisata belanja yang sudah dkenal wisatawan domestik dan mancanegara. Kajian ini bertujuan untuk mengetahui status dan peran Malioboro Mall sebagai objek wisata belanja di Kawasan Malioboro. Metode Kajian yang digunakan adalah induktif kualitatif. Instrumen untuk mengumpulkan data adalah dokumen, kuisioner dan interview. Kuisioner dilakukan terhadap pengunjung Malioboro Mall maupun yang datang di Kawasan Malioboro, untuk melihat persepsi mereka mengenai Malioboro Mall maupun Kawasan Malioboro. Sedangkan interview dilakukan terhadap pengelola Malioboro Mall dan penduduk setempat di sekitar Malioboro Mall. Status berarti suatu kondisi atau situasi. Status Malioboro Mall ada tiga yaitu status Malioboro Mall dilihat dari segi arsitekturnya, properti dan sebagai obyek wisata belanja. Status arsitektur berarti wisatawan datang ke Malioboro Mall karena arsitektur Malioboro Mall yang menarik, status properti berarti Malioboro Mall hanya sebagai fasilitas perbelanjaan bagi wisatawan, status sebagai obyek wisata belanja berarti Malioboro Mall menjadi tujuan utama wisatawan ketika pergi ke Kawasan Malioboro. Hasil analisa ditemukan bahwa status properti adalah status yang paling dominan diantara ketiga status tersebut. Dari sisi peran, Malioboro Mall dapat dianggap sebagai elemen pendukung, bukan sebagai elemen pendukung atau justru malah mengganggu pariwisata di Malioboro. Hasil Kajian menyimpulkan bahwa peran Malioboro Mall mendukung pariwisata di Kawasan Malioboro. Namun ada beberapa faktor yang perlu diperbaiki seperti fasilitas parkir dan kualitas sirkulasi lalu lintas di Kawasan Malioboro, serta perbaikan harga produk dan variasi produk cinderamata di Malioboro Mall.
\end{abstract}

Kata kunci: Kawasan Malioboro, Malioboro Mall, Shopping Mall, Wisata belanja.

\section{PENDAHULUAN}

Perkembangan Pusat Perbelanjaan (Shopping Centre) menjadi sebuah obyek daya tarik wisata dimulai sejak asal mula adanya suatu pusat perbelanjaan. Pusat Perbelanjaan (Shopping Centre) sudah ada sejak abad ke-10 dengan nama Ishfahan 
Status dan Peran ... (Muhammad/ hal. 75-89)

Grand Bazaar, yang sebagian besar tertutup, di Iran ada Teheran Grand Bazaar dengan panjang kurang lebih $10 \mathrm{~km}$ (Sari, 2010). Pada abad ke-15 di Turki ada Istanbul Grand Bazaar yang termasuk pasar tertutup terluas didunia yang mempunyai 58 jalan dan 4.000 pertokoan (Coleman, 2006). Di Oxford Inggris Oxford Covered Market yang dibuka pada tahun 1774 yang sekarang menjadi pusat perbelanjaan terkenal (Sari, 2010).

Sari (2010) berpendapat, pada pertengahan abad 20 seiring perkembangan areal pinggiran kota dan industri otomotif di Amerika Serikat, dibuat sebuah pusat perbelanjaan baru yang jauh dari pusat kota seperti Highland Park Village yang merupakan pusat perbelanjaan pertama di Amerika Serikat. Konsep mall model tertutup pertama kali dirancang oleh seorang Arsitek Austria, Victor Gruen, yaitu Northgale Mall di Seattle, Washington, Amerika Serikat, tahun 1950. Di Inggris ada Chrisp Street Market yang merupakan Shopping Area pertama yang dibangun dengan jalan di depan pertokoan tersebut. Kini Shopping Centre dengan konsep Shopping Mall telah berkembang pesat tidak hanya di Eropa dan Amerika namun di Asia tercatat memiliki Shopping Mall terbesar di dunia yaitu South China Mall di Dongguan, China $\left(892.000 \mathrm{~m}^{2}\right)$ dan Dubai Mall yang masih dalam pelaksanaan $\left(1.100 .000 \mathrm{~m}^{2}\right)$ dan mulai dibuka tahun 2008 (Feinberg, 1991 dan Sari, 2010).

Sekarang ini masing-masing negara di dunia menstigmakan Shopping Mall sebagai tempat tujuan wisata bagi wisatawan khususnya wisatawan mancanegara karena Shopping Centre yang dulunya hanya sebuah tempat berbelanja bagi masyarakat kini telah di kembangkan menjadi wadah menampung aktivitas yang bersifat rekreasi menyesuaikan dengan kebutuhan wisatawan agar lebih menyenangkan (Feinberg, 1991). Singapura telah menjadikan wisata belanja sebagai pemasukan devisa kedua tertinggi dengan jumlah wisatawan yang datang di tahun 2016 mencapai hampir 16,4 juta jiwa dibandingkan dengan jumlah penduduk Singapura pada tahun 2016 sebensar 5,6 juta jiwa, tumbuh sebesar 7,7 persen dibandingkan tahun sebelumnya (Singapore Tourism Board, 2017). Dari laporan tersebut kelompok wisatawan dari Indonesia menempati urutan kedua terbanyak, wisatawan yang paling sering berbelanja di Singapura. Orchard Road yang memiliki berbagai macam retail pertokoan dan Shopping Mall menjadi salah satu kawasan favorit wisatawan di Singapura. Sedangkan di Amerika terdapat Mall of America (MoA) di Bloomington, Minnesota merupakan Shopping Mall yang telah dikunjungi wisatawan mencapai 40 juta wisatawan setiap tahunnya yaitu 8 kali lebih banyak dari jumlah penduduk Minnesota (Sari, 2010). Di Indonesia, Shopping Mall juga berfungsi layaknya sebuah obyek wisata belanja bagi wisatawan seperti di Jakarta terdapat Taman Anggrek Mall, Kelapa Gading Mall dan Megamall Pluit yang telah banyak dikunjungi oleh wisatawan domestic hingga mancanegara.

Globalisasi hingga kini telah melanda berbagai segi kehidupan masyarakat, terutama masyarakat kota-kota besar seperti Yogyakarta yang kini dapat dikatakan sebagai kota metropolitan. Hal ini dapat dilihat dari kriterianya sebagai kawasan perkotaan yang terdiri dari satu kota inti berstatus otonom dan kawasan perkotaan di sekitarnya yang membentuk suatu sistem fungsional. Globalisasi di sektor perdagangan merupakan sektor yang paling dapat dirasakan saat ini. 
Perusahaan transnasional kini tidak hanya menjamah ibukota negara saja, bahkan kini mulai menyebar ke kota-kota besar daerah seperti Kota Yogyakarta.

Layaknya kota metropolitan lainnya, Yogyakarta menjanjikan prospek cerah bagi investor lokal maupun asing dilihat dari peningkatan perkembangan investasi di Propinsi DIY. Pada tahun 2015 mencapai 3,95 trilyun rupiah, naik 0,4 trilyun dari tahun sebelumnya (BKPM DIY, 2017). Hingga di tahun 2017 ini sudah berdiri banyak mall dan hypermarket baru di Yogyakarta, seperti Jogja City Mall, dan Hartono Mall dan Transmart. Munculnya mall-mall baru tersebut merupakan sinyalemen bahwa Yogyakarta sudah mulai mengarah kepada wisata perbelanjaan sebagai potensi wisata baru di Yogyakarta. Malioboro Mall merupakan Shopping Mall pertama di Yogyakarta yang dibangun pada tahun 1993 dan berhasil menjadi sebuah tempat wisata belanja sehingga mendorong para investor untuk menanamkan modal untuk mendirikan pusat-pusat perbelanjaan baru di Yogyakarta.

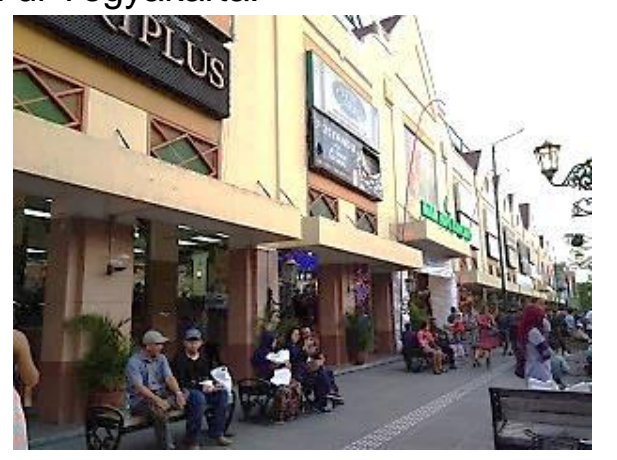

Gambar 1. Kondisi bagian depan Bangunan Malioboro Mall

Malioboro Mall berlokasi di Kawasan Malioboro, yaitu sebuah kawasan perbelanjaan yang terkenal di Yogyakarta. Letaknya berada di sisi sebelah timur jalan yang berlawanan dengan dereta pertokoan dan pedagang kaki lima yang sebagian besar berada di sisi barat jalan. Dengan konsep Shopping Mall, Malioboro Mall memiliki retail-retail yang menjual berbagai produk mulai dari produk fashion, makanan hingga souvenir yang menarik. Malioboro Mall mempunyai peran yang sangat besar terhadap perkembangan pariwisata di Yogyakarta, khususnya wisata perbelanjaan di kawasan Malioboro. Munculnya kesan bahwa suatu Shopping Mall hanyalah sekedar mengejar keuntungan secara ekonomi baik bagi investornya maupun pihak Pemerintah Daerah dapat dikesampingkan, karena tujuan utama sebuah mall adalah untuk melayani para pengunjung atau wisatawan. Malioboro sudah dikenal di seluruh Indonesia hingga negara-negara lain didunia, maka dari itu lokasi Malioboro Mall yang berada di tengah-tengah kawasan Shopping Street Malioboro akan mempunyai peran besar pula terhadap perkembangan wisata perbelanjaan di Yogyakarta.

Pengertian Status dalam Wikipedia adalah kondisi atau keadaan. Penggunaannya bisa berhubungan dengan status sosial, status ekonomi, status legal, status quo dan status sebagai simbol. Dalam Kajian ini, status ditinjau dari kacamata pariwisata mengenai kondisi atau keadaan Malioboro Mall sebagai obyek wisata perbelanjaan. Sementara, peran berhubungan dengan kegunaan dan fungsi yang bisa menjadi peran positif bila bermanfaat dan peran yang negatif apabila merugikan. Peran Malioboro Mall di kawasan Malioboro juga bisa saja mendukung, tidak mendukung atau bahkan mengganggu pariwisata di kawasan Malioboro.

Obyek dan daya tarik wisata menurut UU No. 9 Tahun 1990 menyatakan bahwa obyek dan daya tarik wisata adalah:

"Segala sesuatu yang menjadi sasaran wisata, obyek dan daya tarik wisata ini dapat berupa obyek dan daya tarik wisata 
buatan Tuhan seperti keadaan alam, flora dan fauna, dan juga hasil karya ciptaan manusia yang berwujud museum, peninggalan sejarah, seni budaya, wisata agro dan sebagainya“.

Sammeng (2001) berpendapat, terdapat 2 (dua) kelompok obyek dan daya tarik wisata yaitu otentik/orisinal dan bersifat tiruan (artificial). Kategori tersebut masih menurut Sammeng (2001) terbagi lagi menjadi tiga jenis, yaitu: (1) Obyek wisata alam, misalnya laut, pantai, gunung atau kawah, danau, sungai, flora dan fauna langka, kawasan hutan lindung dan cagar alam, dan pemandangan alam; (2) Obyek wisata budaya, misalnya upacara kelahiran, tarian tradisional, music tradisional, pernikahan dan busana adat, festival budaya, adatistiadat dan pertunjukan; (3) Obyek wisata buatan, misalnya sarana dan prasarana olah raga, tarian rekreasi, taman nasional, kebun binatang dan pusat perbelanjaan.

Beberapa hal yang harus diperhatikan dalam pengembangan suatu daerah tujuan wisata harus memenuhi 3 (tiga) syarat (Yoeti, 1983), yaitu (1) Daerah tersebut harus mempunyai "something to see" artinya harus mempunyai daya tarik khusus yang berbeda dengan yang dimiliki daerah lain; (2) Daerah tersebut harus tersedia "something to do" yaitu tempat tersebut harus menyediakan fasilitas rekreasi atau amusement yang dapat memberikan rasa nyaman; (3) Daerah tersebut harus tersedia "something to buy" yaitu fasilitas untuk belanja, terutama souvenir dan kerajinan rakyat. Tersedia juga saranasarana pendukung seperti money changer, bank, kantor pos, sarana telekomunikasi, dan lain-lain.

Shopping adalah sebuah aktivitas menyenangkan ketika sedang berlibur dan banyak yang berpendapat bahwa shopping merupakan atraksi dan motivasi utama ketika bepergian. Shopping tourism atau wisata belanja adalah salah satu aktivitas yang paling banyak dilakukan wisatawan dan banyak ilmuwan sependapat wisata belanja sebagai hal penting yang berhubungan dengan masalah ekonomi, psikologi dan sosial yang dicari oleh wisatawan (Gunn, 1988, MacCannel 2002, Mclntosh and Goeldner 1990 dalam Snepenger, 2003).

Butler (1991) mengatakan bahwa hubungan antara shopping dan tourism dibagi menjadi dua kategori, yaitu: (1) Motif utama melakukan perjalanan wisata adalah shopping; (2) Shopping adalah aktivitas kedua selama perjalanan wisata dimana motivasi utamanya adalah aktivitas wisata lain seperti sunbathing, ekotourism, dan lain-lain. Masih menurut Butler (1991), ada 3 (tiga) faktor utama yang mempengaruhi bahwa shopping sebagai motif utama ketika berwisata, yaitu: (1) Benda atau barang yang dicari; (2) Tujuan wisata yang dituju; (3) Keuntungan dari harga benda atau barang tersebut.

Shopping Centre atau pusat perbelanjaan, menurut International Council of Shopping Center (ICSC) (1999) dan Barry (1985) dalam Yaqin (2017), memiliki makna sebagai kumpulan retail dan perusahaan komersial lain yang direncanakan, dikembangkan, dimiliki, dan dikelola sebagai sebuah kepemilikan tunggal, yang menyediakan tempat parkir sendiri. Ukuran besarnya pusat perbelanjaan dan arah orientasi dipengaruhi oleh karakteristik pasar dari daerah perdagangan dimana pusat perbelanjaan itu berada. Barry (1985) dalam Yaqin (2017), mengelompokkan pusat perbelanjaan berdasarkan bentuk fisik menjadi 7 (tujuh) kategori, yaitu: (1) Shopping Street, yang merupakan komplek toko berderet disepanjang sisi jalan 
membentuk pola pita; (2) Shopping Centre, yaitu komplek pertokoan yang terdiri dari toko yang disewakan atau dijual;

Shopping Percint, yaitu sebuah komplek pertokoan dimana pada bagian depan stand toko menghadap ke ruang bebas; (4) Departement Store, yaitu sebuah toko besar yang terdiri dari beberapa lantai dan menjual berbagai macam barang dan pakaian, memiliki luasan lantai $\pm 10.000 \mathrm{~s} / \mathrm{d}$ $20.000 \mathrm{~m}^{2}$, dan memiliki tata cara peletakan barang yang khusus; (5) Supermarket, yaitu toko yang menjual kebutuhan sehari hari dengan sistem self-service, memiliki luasan lantai $\pm 5.000 \mathrm{~s} / \mathrm{d} 7.000 \mathrm{~m}^{2}$, dan memiliki area penjualan bahan makanan yang tidak melebihi $15 \%$ dari seluruh area penjualan; (6) Departement Store dan Supermarket, merupakan bentuk-bentuk perbelanjaan modern yang menggabungkan dua jenis pusat perbelanjaan; (7) Superstore, yaitu toko yang menjual berbagai macam barang kebutuhan sandang dengan sistem selfservice dan biasanya hanya 1 lantai dengan luas area penjualan minimal $2.500 \mathrm{~m}^{2}$ dan luasan lantai $\pm 5.000 \mathrm{~s} / \mathrm{d} 7.000 \mathrm{~m}^{2}$.

Dilihat berdasarkan luas areal pelayanan, menurut U.L.I standar (1977) dan Edgar (1976) dalam Yaqin (2017), pusat perbelanjaan dikategorikan menjadi 3 (tiga), yaitu: (1) Regional Shopping Centre, yaitu terdiri dari dua atau lebih departement store dengan skala pelayanan antara 150.000400.000 penduduk, terletak di lokasi strategis yang tergabung dalam lokasi perkantoran, rekreasi dan seni, memiliki luas areal $27.870 \mathrm{~s} / \mathrm{d} 29.900 \mathrm{~m}^{2}$; (2) Community Shopping Centre, yaitu terdiri atas junior department store dan supermarket dengan jangkauan pelayanan antara 40.000-150.000 penduduk yang terletak pada lokasi yang mendekati pusatpusat kota, memiliki luas areal 9.260-23.225 m²; (3) Neighbourhood Shopping Centre, yaitu memiliki unit terbesar berbentuk supermarket yang berada pada suatu lingkungan tertentu, memiliki jangkauan pelayanan $5.000 \mathrm{~s} / \mathrm{d} 40.000$ penduduk dengan luas areal $2.720 \mathrm{~s} / \mathrm{d} 9.290 \mathrm{~m}^{2}$.

Mall secara tradisional dapat diartikan sebagai suatu daerah yang dilindungi pohon-pohon dan biasanya berfungsi sebagai jalan umum atau dipergunakan untuk area pejalan kaki (Yaqin, 2017). Penggunaannya saat ini, Mall diartikan sebagai suatu jenis yang baru dari jalan atau plaza pada pusat perdagangan kota yag diorientasikan bagi jalur pejalan kaki serta dilayani angkutan umum. Terdapat beberapa jenis Mall, yaitu: (1) Full Mall, yaitu Mall yang terbentuk dengan menutup jalan yang pada mulanya sebagai arus kendaraan yang kemudian dikembangkan menjadi jalan pedestrian atau plaza; (2) Transit Mall, yaitu Mall yang dikembangkan melalui pemindahan arus lalu lintas kendaraan pada suatu jalan yang hanya memperbolehkan transportasi umum; (3) Semi Mall, yaitu terbentuk dari pengurangan jumlah parkir dan lalu lintas, sehingga area untuk pejalan kaki menjadi lebih besar.

Shopping Mall, masih menurut Yaqin (2017), berawal dari kata pedestrian mall yang berarti tempat di mana orang lewat (pergerakan manusia). Shopping Mall adalah satu atau kumpulan bangunan yang terdiri dari toko-toko dengan pedestrian/tempat pejalan kaki yang saling berhubungan agar memudahkan akses pengunjung, dan biasanya arealnya tertutup (enclosed). Yaqin (2017) juga menjelaskan bahwa berdasarkan fungsi dan perkembangannya, terdapat 3 (tiga) bentuk tipologi Shopping Mall, yaitu: (1) Sistem terbuka (Open Mall), yaitu sebuah mall tanpa diberi pelingkup agar memberikan kesan luas tetapi berpengaruh terhadap 
kenyamanan terhadap gangguan cuaca dan memiliki retail yang saling berjarak; (2) Sistem Tertutup (Enclosed Mall), yaitu seluruh bagian mall diberi pelingkup sehingga memberikan rasa aman dan nyaman serta menyatu dalam bangunan; (3) Sistem Terpadu, yaitu gabungann antara mall terbuka dan tertutup. Alasannya untuk mengantisipasi pengaruh kontrol penghawaan, boros energi, serta mahalnya biaya perawatan.

\section{METODE}

Secara umum, ada beberapa tujuan yang ingin dicapai dari Kajian ini, yaitu: (1) Untuk menemukenali peran dan status Malioboro Mall sebagai bagian dari pusat perbelanjaan yang sekaligus juga sebagai obyek wisata belanja, (2) Untuk membuktikan bahwa Malioboro Mall adalah obyek wisata khususnya wisata perbelanjaan, (3) Penegasan tentang Malioboro Mall sebagai obyek wisata penting di Yogyakarta. Berdasarkan masalah dan tujuan yang dipecahkan dan dicapai dalam Kajian ini, maka metode yang digunakan dalam analisis data adalah metode induktif kualitatif eksploratif dengan pengamatan secara empiric melalui observasi, wawancara mendalam (indepth interview) dan penyebaran kuisioner khusus kepada wisatawan. Metode ini dimaksudkan untuk memberikan analisis dan deskripsi berdasarkan data dan informasi yang diperoleh dari hasil Kajian atau obyek yang diteliti.

Bogdan dan Taylor (1975) berpendapat, dalam Moleong (2002), kajian kualitatif sebagai prosedur kajian yang menghasilkan data dekkriptif berupa kata-kata tertulis atau lisan dari orang-orang dan perilaku yang diamati. Metode deskriptif diartikan sebagai prosedur pemecahan masalah dengan menggambarkan keadaan subyek/obyek Kajian berdasarkan fakta-fakta yang tampak dan usaha mengemukakan hubungannya satu dengan yang lainnya di dalam aspekaspek yang diselidiki. Wilayah Kajian dalam Kajian ini terbagi menjadi 2 (dua), yaitu:

a. Wilayah Kajian intensif, yaitu Malioboro Mall sebagai lokus utama Kajian

b. Wilayah Kajian ekstensif, yaitu kawasan Malioboro, yaitu pada jalan kanan kirinya terdapat pertokoan yang berhubungan dengan wisata belanja dimulai dari jalan Malioboro hingga jalan A. Yani.

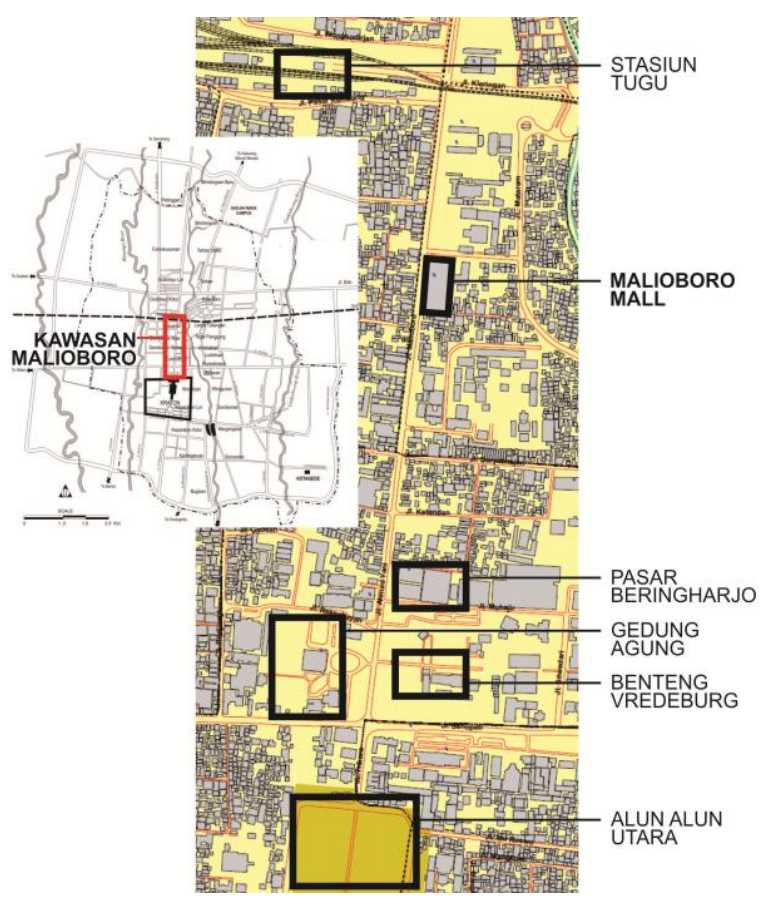

Gambar 2. Wilayah Kajian Malioboro

Metode yang digunakan selama proses memperoleh data yaitu melalui pengumpulan data primer, yaitu: (1) Kuisioner yang dibagikan kepada pengunjung dan non pengunjung Malioboro Mall; (2) Observasi lapangan untuk melakukan pengamatan dan pengecekan terhadap kondisi bangunan Malioboro Mall dan wisata belanjanya. Parameter amatan berupa analisa persepsi wisatawan tentang Malioboro, analisa persepsi wisatawan tentang Malioboro Mall dan persepsi wisatawan mengenai wisata di luar dari 
Malioboro Mall; (3) Interview yang dilakukan terhadap stakeholder yang berhubungan dengan Malioboro Mall sebagai sebuah property. Kemudian melalui data sekunder, yaitu data yang diperoleh dari berbagai dokumen yang terkait dengan Malioboro Mall dan wisata belanjanya.

Malioboro merupakan landmark kota Yogyakarta. Lokasinya yang berada di pusat kota membuat Malioboro berkembang pesat menjadi sebuah kawasan komersial didukung bangunan-bangunan pusat perbelanjaan disekitarnya. Malioboro sebagai salah satu pengal jalur yang ada di tengah koota Yogyakarta. Disamping memiliki peran fungsional formal dan informal bagi kehidupan warga, juga mempunyai arti historis-kultural.

Yogyakarta yang terkenal sebagai kota pariwisata memiliki keunggulan dari segi potensi alam dan sosial budaya yang kemudian muncul potensi sebagai tujuan wisata belanja, seperti kawasan Malioboro dan JI. Solo. Proses ini terjadi di era 80-an dimana pariwisata mulai berkembang pesat di Kawasan Malioboro dengan munculnya kegiatan perdagangan dan jasa skala besar seperti deretan pertokoan, penjual cinderamata, kemudian perhotelan yang kesemuanya mendukung pariwisata di Kota Yogyakarta. Selain wisata belanja, terdapat bangunan bersejarah yang menarik dikunjungi wisatawan di kawasan Malioboro seperti Benteng Vredeburg dan Istana Gedung Agung.

Malioboro adalah kawasan pusat kota yang aktivitasnya padat, mulai dari aktivitas perdagangan, pariwisata, perkantoran, permukiman, dan lain sebagainya. Oleh karena itu perlu didukung aksesibilitas yang bisa menjadi sarana pendukung kawasan padat Malioboro.

INERSIA, Vol. XIV No. 1, Mei 2018
Tabel 1. Kondisi Kepadatan Lalu lintas Jalan Malioboro

\begin{tabular}{|c|c|c|c|c|}
\hline Ruas Jalan & $\begin{array}{l}\text { Non } \\
\text { Motor }\end{array}$ & $\begin{array}{l}\text { Motor } \\
\text { cycle }\end{array}$ & $\begin{array}{c}\text { Light } \\
\text { Vehicle }\end{array}$ & $\begin{array}{c}\text { Heavy } \\
\text { Vehicle }\end{array}$ \\
\hline $\begin{array}{c}\text { Jl. Abu Bakar } \\
\text { Ali }\end{array}$ & 2.035 & 45.678 & 14.641 & 900 \\
\hline $\begin{array}{l}\text { Jl. Malioboro } \\
\text { (Sarkem- } \\
\text { Sosrowijayan) }\end{array}$ & 7.536 & 65.887 & 21.095 & 1.077 \\
\hline $\begin{array}{c}\text { Jl. Perwakilan } \\
\text { (ABA- } \\
\text { Perwakilan) }\end{array}$ & 2.463 & 54.869 & 15.737 & 1.610 \\
\hline $\begin{array}{l}\text { Jl. Malioboro } \\
\text { (Sosrowijayan } \\
\text {-Perwakilan) }\end{array}$ & 6.627 & 58.300 & 18.752 & 1.008 \\
\hline $\begin{array}{c}\text { Jl. Malioboro } \\
\text { (Perwakilan- } \\
\text { Dagen) }\end{array}$ & 5.354 & 51.013 & 16.166 & 997 \\
\hline $\begin{array}{c}\text { Jl. Malioboro } \\
\text { (Dagen- } \\
\text { Pajeksan) }\end{array}$ & 4.159 & 47.681 & 14.832 & 996 \\
\hline $\begin{array}{l}\text { Jl. Mataram } \\
\text { (Perwakilan- } \\
\text { Mas Suharto) }\end{array}$ & 1.805 & 52.976 & 11.411 & 1.328 \\
\hline $\begin{array}{c}\text { Jl. Mataram } \\
\text { (Mas } \\
\text { Suharto- } \\
\text { Juminahan) }\end{array}$ & 3.914 & 72.443 & 14.876 & 1.887 \\
\hline
\end{tabular}

Sumber: PUSTRAL UGM (2013)

Area parkir motor, mobil, dan bus pariwisata kawasan Malioboro berada di Taman Khusus Parkir Abu Bakar Ali. Area parkir ini resmi direlokasi pada tahun 2016 karena ingin mengembalikan kembali fungsi dari area pedestrian di kawasan Malioboro yang sebelumnya dialihfungsikan menjadi zona parkir.

Pedestrian di sepanjang jalan Malioboro baik di sisi barat maupun di sisi timur sangat padat oleh pejalan kaki dan pedagang kaki lima yang berjualan. Pejalan kaki menggunakan semua area untuk berjalan, baik di trotoar maupun diluar trotoar. Pejalan kaki juga menggunakan semua bagian jalan ketika mnyebrang dan hampir sebagian besar tidak melalui zebra cross (PUSTRAL UGM, 2013). Selain pertokoan juga tersedia pusat perbelanjaan 
di kawasan Malioboro yang terdiri dari beberapa jenis, yaitu: (1) Shopping Mall, yaitu Malioboro Mall yang menjadi titik lokus utama pada Kajian ini; $\quad$ (2) Shopping Centre, terdapat Ramai Shopping Centre yang memiliki 4 lantai dan luas tanah 5.000 $\mathrm{m}^{2}$ dan luas bangunan $12.000 \mathrm{~m}^{2}$ dengan supermarket dan department store didalamnya; (3) Department Store,terdapat Matahari Department Store yang menawarkan produk-produk fashion dan Ramayana Department Store, yang terletak di utara Malioboro dan sisi barat jalan Malioboro. Pasar (Market) yang ada di kawasan Malioboro adalah Pasar Beringharjo. Pasar Beringharjo merupakan pasar tradisional tertua di Yogyakarta, memiliki 3 lantai dan sekitar 7.000 pedagang menggelar dagangannya mulai dari peralatan rumah tangga, elektronik, dan macam-macam batik di jual disini. Pedagang Kaki Lima (PKL) dapat ditemukan di sepanjang Malioboro. Menurut Sholihah (2005), PKL tersebut menawarkan beragam produk mulai dari pakaian, kerajinan tangan hingga makanan. PKL ada 2 (dua) jenis menurut lokasi dan jenis produk yang di jual, yaitu: (1) Di sisi timur jalan, terdapat pedagang yang menjual makanan dan minuman dan sebagian besar terletak di depan hotel Inna Garuda dan Gedung DPRD dan juga di depan Pasar Beringharjo; (2) Di sisi barat jalan, terdapat pedagang kerajinan yang menjual produkproduk souvenir seperti batik fashion, sendal, dompet, pernak-pernik, kerajinan perak, lukisan dan lain-lain.

Malioboro Mall adalah Shopping Mall pertama di Yogyakarta yang berdiri di atas tanah seluas $4.285 \mathrm{~m}^{2}$ dan didirikan pada 27 November 1993. Malioboro Mall dibangun atas kerjasama antara Pemerintah Propinsi D.I Yogyakarta dengan PT Yogya Indah Sejahtera (YIS). Lokasinya yang strategis berada di kawasan wisata
Malioboro menguntungkan bagi Malioboro Mall dan hingga kini menjadi sangat terkenal menjadi salah satu tujuan wisatawan untuk berbelanja produk dengan jumlah kunjungan 15-20 ribu di hari biasa dan 25 ribu pengunjung di akhir pekan (Sholihah, 2005).

Konsep desain dari Malioboro Mall ini merupakan pengelolaan facade dan arcade yaitu merupakan bentuk pengulangan dari bangunan-bangunan di sepanjang jalan Malioboro yang sebagian besar menggunakan konsep percampuran antara arsitektur tradisional dan modern. Konsep hubungan ruang pada Malioboro Mall menggunakan koridor tunggal (Gambar 3) dengan anchor tenant menempati ujung bangunan, sehingga retail-retail kecil dibangun di sepanjang atrium, foodcourt diletakkan di lantai paling atas agar menarik pengunjung agar naik ke atas dengan tujuan agar retail-retail yang ada mempunyai kesempatan yang sama untuk dikunjungi.

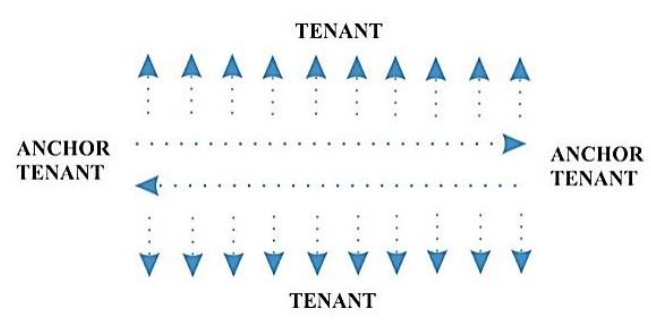

Gambar 3. Model hubungan ruang dalam bangunan Malioboro Mall

(Sumber: Hasil survey lapangan, 2017)

Sebagai obyek wisata belanja bagi wisatawan, Malioboro menawarkan berbagai macam produk yang bisa dijadikan souvenir, mulai dari produk fashion, makanan hingga kerajinan. Jenis pertokoan yang ada di Malioboro antara lain: (1) Toko souvenir, seperti toko batik dan toko barang kerajinan (souvenir craft); (2) Toko fashion, yang menjual produk-produk fashion untuk wanita, pria, remaja, dan anak-anak; (3) 
Toko makanan atau restoran, yang menjual produk-produk makanan mulai dari fast food, western food, masakan tradisional, dan lain-lain; (4) Toko buku; (5) Toko sepatu dan sandal; (6) Toko tas; (7) Toko alat rumah tangga; (8) Toko tekstil; (9) Toko musik; (9) Toko perhiasan; (10) Toko elektronik; (11) Toko arloji; (12) Toko obatobatan; (13) Toko Otomotif; dan (14) Toko serba ada.

Berbagai fasilitas disediakan di Malioboro Mall untuk menunjang fungsinya sebagai pusat perbelanjaan, yaitu: (1) Parkir, fasilitas parkir sepeda motor terletak di sepanjang sisi timur jalan Malioboro dan parkir mobil berada di sisi utara Malioboro Mall di sepanjang jalan Perwakilan; (2) ATM, tersedia fasilitas ATM bank Mandiri di pintu masuk utara, bank Danamon dan bank Lippo di pintu masuk selatan, dan bank BCA di bagian upper ground floor (lantai dasar); (3) Toilet di bagian timur Mall tiap lantai; (4) Foodcourt yang bernama Food Point di lantai 3 Mall, dan (5) Game Zone, terletak di lantai 3 Mall dengan nama Fun Zone yang menyediakan beberapa fasilitas bermain untuk anak-anak. Berbagai fasilitas di setiap lantai di Malioboro dapat dilihat pada Gambar 4, berikut deskripsinya:

a. Basement, diperuntukkan untuk parkir mobil yang bisa menampung hingga 120 mobil, dan juga terdapat mushola, ruang staff dan ruang security.

b. Lower Ground Floor, terdapat Hero Supermarket sebagai anchor tenant, terdapat toko buku Gramedia dan
Periplus, beberapa retail yang menjual produk makanan seperti Shihin Taiwan, Tea Preso, Baskin Robbin, terdapat retail fashion seperti Dagelan dan Mini So serta terdapat juga retail salon kecantikan Johny Andrean.

c. Upper Ground Floor, terdapat retail-retail yang menjual produk fashion dari beragam merk terkenal seperti Hammer, Lee Cooper, Post Boy, Gosh, Eiger, Buccheri, Westime dan Planet Sport. Ada juga retail produk sepatu seperti Shoe Line dan Camel Active, beberapa retail perhiasan seperti Madonna, PLG dan Julia Jewelry dan retail produk makanan yaitu Mc. Donalds.

d. Lantai 1 (1st Floor), didominasi oleh retail produk fashion dan sepatu seperti Matahari Departement Store, Giordano, $C$ \& F, Pollo, The Executive, Wrangler, DC, Naughty, OSZCLTH, Sport Station, Rumah Warna, Gaudi, D.C, Converse dan Bata. Retail produk makanan seperti Excelso, Kopi Luwak dan Es Teler 77. Terdapat juga fasilitas ATM Mandiri dan Link di rest area.

e. Lantai 2 (2nd Floor), didominasi oleh retail produk fashion dan Sepatu seperti Matahari Departement Store, Skecher, Kidz Station, Crocs, Hush Puppies, Reebok, Hava, Hardware, Planet Surf, dan Athlete's Foot. Terdapat retail produk makanan seperti Pizza Hut dan fasilitas ATM BCA di rest area.

f. Lantai 3 (3rd Floor), digunakan untuk fasilitas rekreasi seperti fun world dan food court. 


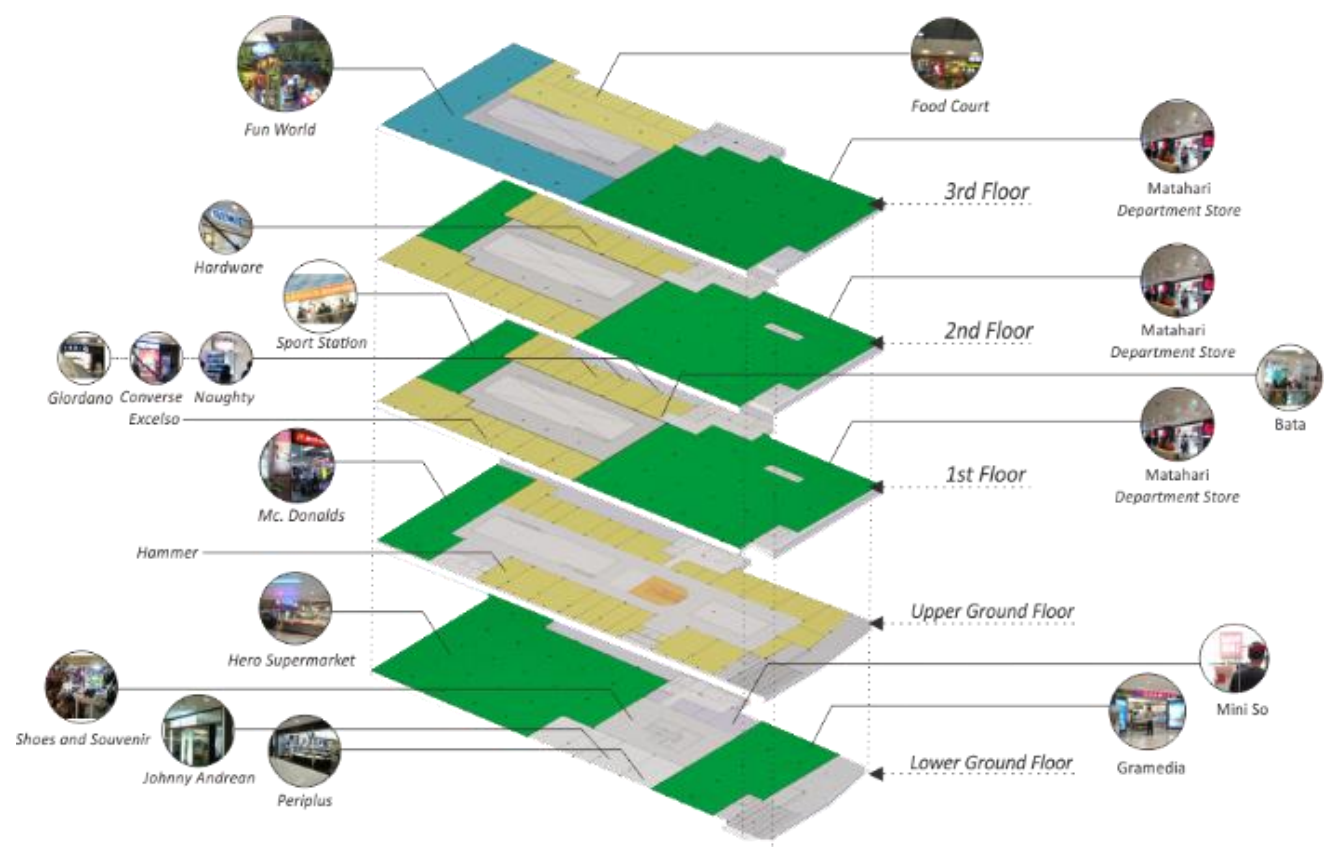

Gambar 4. Kondisi Peruangan dan Interior Malioboro Mall (Sumber: Hasil survey lapangan, 2017)

\section{HASIL DAN PEMBAHASAN}

Kajian ini meliputi analisa potensi Malioboro Mall sebagai obyek wisata belanja dari segi destinasi, Potensi Malioboro Mall sebagai obyek wisata belanja fashion di Kawasan Malioboro, Potensi Malioboro Mall sebagai obyek wisata produk souvenir di Kawasan Malioboro, dan Potensi Malioboro Mall sebagai obyek wisata kuliner di Kawasan Malioboro. Berikut pembahasan dari analisa tersebut:

a. Potensi Malioboro Mall sebagai obyek wisata belanja dari segi destinasi. Lokasi Malioboro Mall di kawasan shopping street seperti Kawasan Malioboro memiliki beberapa keuntungan, antara lain: (1) Kedekatan dengan obyek wisata lain selain belanja, seperti obyek wisata heritage seperti Benteng Vredeburg, Istana Gedung Agung dan Taman sari sehingga menjadi suatu kombinasi wisata menarik; (2) Kedekatan dengan Stasiun Tugu sebagai Stasiun Kota Yogyakarta, sehingga wisatawan yang datang dari luar kota dapat langsung menuju Malioboro Mall; (3) Kedekatan dengan berbagai amenitas, seperti restoran dan rumah makan yang ada di Kawasan Malioboro; (4) Kedekatan dengan berbagai akomodasi yang ada di Kawasan Malioboro, seperti hotel Ibis, hotel Inna Garuda, hotel Mutiara, Melia Purosani dan lain-lain.

b. Potensi Malioboro Mall sebagai obyek wisata belanja fashion di Kawasan Malioboro. Banyaknya pilihan retail yang menjual berbagai produk seperti fashion dari berbagai pilihan merk ternama dengan kualitas yang baik merupakan keunggulan dari Malioboro Mall. Beberapa retail juga tidak jarang memberikan promo diskon untuk produk fashion mereka, sehingga muncul persepsi masyarakat bahwa Malioboro Mall adalah sebuah obyek wisata 
berbelanja fashion yang lengkap dan menarik untuk dikunjungi.

c. Potensi Malioboro Mall sebagai obyek wisata produk souvenir di Kawasan Malioboro. Produk-produk kerajinan di Malioboro Mall akan menarik minat para wisatawan dan penempatan retailnya di lantai upper ground floor dan lower ground floor akan lebih mudah ditemui ketika pengunjung memasuki Malioboro Mall.

d. Potensi Malioboro Mall sebagai obyek wisata kuliner di Kawasan Malioboro. Malioboro Mall bisa menjadi tujuan wisata kuliner di Malioboro karena kelengkapan dari segi produk makanan yang dijual untuk semua segmen masyarakat mulai dari fast food hingga masakan tradisional.

Malioboro Mall adalah pusat perbelanjaan dengan konsep Shopping Mall di Kawasan Malioboro yang memiliki bangunan yang megah dan menarik dari segi arsitektural dari pada pusat perbelanjaan dan pertokoan lain di Malioboro, sehingga mempunyai image yang lebih tinggi dari pada pusat perbelanjaan lain di Malioboro. Bahakan menurut Kajian tentang Kawasan Malioboro menyebutkan bahwa Malioboro Mall mempunyai image interest yang paling tinggi di antara pertokoan dan pusat perbelanjaan lain di Malioboro (Solihah, 2005).

Berdasarkan hasil kuesioner, diperoleh data bahwa jenis produk yang dijual di Malioboro Mall tidak jauh berbeda dengan mall-mall pada umumnya dengan produk utamanya adalah fashion (garmen) 95\%, sementara sisanya adalah produk makanan dan lainnya. Hasil kuesioner yang disebarkan juga mendata mengenai karakter pasar. Usia responden ternyata yang terbanyak adalah kelompok umur $16-30$ tahun (46\%), maka dapat dikatakan bahwa pelajar dan INERSIA, Vol. XIV No. 1, Mei 2018 mahasiswa adalah potensi market terbesar di Kawasan Malioboro maupun Malioboro Mall. Pengunjung terbesar di Kawasan Malioboro dan Malioboro Mall adalah wisatawan domestik yang berasal dari luar Provinsi DIY dan Jawa Tengah (52\%). Hal ini membuktikan bahwa wisatawan domestik adalah potensi pasaryang terbesar untuk Kawasan Malioboro dan Malioboro Mall.

Dilihat secara destinasi, Malioboro Mall tidak bisa dilepaskan dari Malioboro sebagai kawasan wisata belanja sehingga kondisi yang terjadi akan berdampak pula terhadap keberadaan Malioboro Mall. Malioboro yang sudah pada tahap stagnan dari segi daerah tujuan wisata juga berdampak terhadap berbagai jenis termasuk masalah transportasi menuju Malioboro Mall. Kawasan Malioboro sebagai satu kawasan pariwisata telah masuk tahap Stagnation (stagnan) terlihat dengan:

a. Penggunaan lahan dan bangunan yang tidak terkendali telah menghilangkan jejak sejarah yang ada.

b. Jumlah PKL yang makin padat dan menyebar, menyita sebagian besar trotoar untuk pejalan kaki.

c. Adanya kekumuhan karena budaya kurang bersih di antara pelaku kegiatan di Malioboro.

Dari berbagai permasalahan tersebut, maka perlu adanya suatu Rejuvenation atau peremajaan kembali terhadap Malioboro.Status berkenaan dengan suatu kondisi atau keadaan, hal itu bisa menyangkut mengenai sosial, ekonomi, hukum, legal ataupun simbol. Berkenaan dengan Malioboro Mall sendiri maka disini peneliti memandang statusnya dari kacamata pariwisata. Malioboro Mall adalah suatu bentuk pusat perbelanjaan dengan konsep Shopping Mall. Tiap harinya 
Malioboro Mall dikunjungi wisatawan baik lokal maupun mancanegara. Hal ini berarti Malioboro Mall menjadi tujuan wisata bagi wisatawan, namun tidak apat dipisahkan bahwa Malioboro Mall adalah sebuah bangunan yang mempunyai nilai arsitektur, sebuah properti dengan berbagai produk yang dijual dan sebuah obyek wiata belanja bagi wisatawan. Oleh karena itu, jika dipandang dari sudut pariwisata, maka status Malioboro Mall dapat dilihat dari 3 sisi: (1) Status Malioboro Mall dilihat dari segi Arsitektur (2) Status Malioboro Mall dilihat dari segi Properti (3) Status Malioboro Mall dilihat sebagai obyek wisata.

Peran dikaitkan dengan fungsi dan kegunaan. Jika dikaitkan dengan Malioboro Mall, maka akan berhubungan dengan fungsi dan kegunaan Malioboro Mall sendiri. Malioboro Mall, jika dilihat dari kacamata pariwisata, maka berkaitan dengan Malioboro Mall sebagai sebuah wisata belanja bagi wisatawan yang mengunjungi Malioboro. Dalam hal ini, peran Malioboro Mall dalam perkembangan wisata di Malioboro perlu di analisa lebih lanjut apakah peran tersebut mendukung, tidak mendukung sama sekali, atau bahkan mengganggu perkembangan wisata di Malioboro.

a. Mendukung, jika Malioboro Mall memberikan banyak manfaat terhadap perkembangan wisata di Kawasan Malioboro.

b. Tidak mendukung, jika Malioboro Mall tidak memberikan manfaat sama sekali terhadap perkembangan wisata di Kawasan Malioboro.

c. Mengganggu, jika keberadaan di Malioboro Mall di Kawasan Malioboro lebih banyak memberikan banyak kerugian dari pada manfaat dalam perkembangan wisata di Kawasan Malioboro.
Berikut analisis jabarannya.

1. Peran Malioboro Mall yang Mendukung Pariwisata di Kawasan Malioboro:

a. Fasad perbelanjaan yang menghadap jalan paling panjang dan megah di Malioboro adalah Malioboro Mall, sehingga menimbulkan ketertarikan wisatawan untuk mengunjungi Malioboro Mall.

b. Segi arsitektur yang menarik merupakan perpaduan antara gaya arsitektur tradisional dan Modern dan merupakan satu-satunya pusat perbelanjaan dengan konsep Shopping Mall.

c. Malioboro Mall adalah pusat perbelanjaan yang lebih besar dari yang lain. Dengan luasan bangunan yang besar dapat menampung jumlah yang besar juga.

d. Malioboro Mall memiliki potensi sebagai wisata belanja fashion, hal ini bisa terlihat dari jenis retail paling banyak adalah fashion retail daripada retail lain.

e. Malioboro Mall memiliki potensi sebagai wisata kuliner. Berdasarkan hasil observasi, retail yang menjual produk makanan yang ada sangat lengkap mulai dari fast food, cafe, dan berbagai jenis makanan yang ada di food court.

f. Adanya produk-produk souvenir yang beragam di Malioboro Mall pastinya menarik minat wisatawan yang mengunjungi Malioboro Mall.

g. Berdasarkan hasil interview, Malioboro Mall memberikan banyak manfaat terhadap beberapa stakeholder yang terlibat dalam Malioboro Mall, antara lain: (1) Pemerintah propnsi mendapat keuntungan dari pemasukan Pendapatan Hasil Daerah (PAD) dari penyewaan aset tanah kepada pengelola; (2) Manajemen

INERSIA, Vol. XIV No. 1, Mei 2018 
mendapatkan keuntungan dari sistem sewa ruangannya; (3) Penyewa mendapatkan keuntungan dari penjualan produknya; (4) Masyarakat sekitar mendapatkan keuntungan dari kontrakan kos bagi karyawan mall, rumah makan yang tambah ramai dan parkir kendaraan bagi karyawan.

2. Peran Malioboro Mall yang Tidak Mendukung Pariwisata di Kawasan Malioboro:

a. Berdasarkan observasi, adanya Malioboro Mall volume parkir bertambah. Ruang parkir basement di Kawasan Malioboro selalu penuh.

b. Berdasarkan hasil kuisioner, wisatawan yang tidak mengunjungi Malioboro Mall lebih dikarenakan harga produk yang tinggi.

c. Malioboro Mall sendiri masih memiliki produk souvenir yang sangat sedikit dan temporer saja

d. Berdasarkan data kuisioer, wisatawan belum tentu mengujungi Malioboro Mall. Wisatawan lebih menggemari Pasar Berigharjo dan PKL karena dari segi harga produknya yang lebih miring.

e. Berdasarkan hasil interview, Malioboro Mall juga memberikan dampak negatif berupa pencemaran lingkungan dan kontribusi yang kurang terhadap masyarakat sekitar.

3. Peran Malioboro Mall yang Mengganggu.

Hasil analisa observasi maupun kuisioner, tidak ada satupun alasan yang mengganggu kegiatan pariwisata di Kawasan Malioboro, yang menyebabkan Malioboro Mall harus dihilangkan atau di bongkar.

Dari berbagai analisa di atas dapat disimpulkan bahwa Malioboro Mall berperan mendukung pariwisata di Malioboro. Ini berarti Malioboro Mall banyak memberikan INERSIA, Vol. XIV No. 1, Mei 2018 manfaat dalam bentuk fasilitas perbelanjaan bagi wisatawan ketika ke Malioboro. Namun ada beberapa hal yang perlu di perbaiki uuntuk menjadikan Malioboro Mall dan kawasan Malioboro menjadi tujuan wisata belanja bagi wisatawan domestik maupun mancanegara.

\section{SIMPULAN}

Malioboro Mall sebagai bentuk wisata belanja di Kawasan Malioboro statusnya dapat dilihat dari tiga sisi, yakni dari segi Arsitektur, Properti dan sebagai obyek wisata belanja. Malioboro Mall sebuah pusat perbelanjaan dengan konsep Mall di kawasan wisata belanja Malioboro. Mall sendiri adalah salah satu bentuk properti. Hasil temuan membuktikan status Malioboro Mall yang paling dominan adalah sebagai properti.Hal ini berarti Malioboro Mall statusnya hanya sebagai fasilitas perbelanjaan bagi wisatawan. Sedangkan motif utamanya adalah mengunjungi obyek wisata lain di Kawasan Malioboro

Obyek wisata adalah tujuan utama wisatawan ketika bepergian. Malioboro Mall bisa dikatakan sebagai obyek wisata belanja jika wisatawan yang datang ke Malioboro khusus mendatangi Malioboro Mall untuk berbelanja. Hasil temuan menyebutkan: 1) Produk (Merchandise): Wisatawan yang mengunjungi Malioboro Mall lebih tertarik dan membeli produk fashion daripada produk khas atau souvenir yang merupakan daya tarik obyek wisata belanja; 2) Tujuan Wisata (Destination) : Malioboro Mall sebagai pusat perbelanjaan yang sudah terkenal, namun sebagian besar wisatawan tidak mengunjungi Malioboro Mall. Sebagian berbelanja dan sebagian hanya berjalan-jalan saja; 3) Harga (Price): Harga produk-produk di Malioboro Mall tergolong tinggi, tidak dapat di nego dan beberapa harga produk lebih 
mahal daripada tempat lain di kawasan Malioboro. Sedangkan Pasar Beringharjo dan PKL lebih banyak diminati wisatawan.

Dari hasil temuan disebutkan Malioboro Mall bukanlah suatu obyek wisata, namun lebih kepada sebuah fasilitas perbelanjaan bagi wisatawan. Peran Malioboro Mall sendiri sangat besar dalam hal mendukung wisata belanja di Kawasan Malioboro.

\section{DAFTAR RUJUKAN}

Badan Kerjasama dan Penanaman Modal (BKPM) Provinsi Daerah Istimewa Yogyakarta. 2017. Laporan Kinerja Instansi Pemerintah Provinsi Daerah Istimewa Yogyakarta tahun 2017.

Beddington, Nadine. 1982. Design for Shopping Centers. Butterworth Scientific. London.

Butler, Richard W. 1991. West Edmonton Mall as a Tourist Attraction. The Canadian Geographer Journal, John Wiley and Sons Publisher.

Coleman, Peter. 2006. Shopping Environmen Evolution, Planning and Design. Burlington: Architectural Press.

Edgar, Lion P. Eng. 1976. Shopping Center, Planning and Administration. John Willey and Sons.Inc. USA.

Feinberg, Richard, and Meoli Jennifer. 1991. A Brief History of The Mall. Journal of Advances in Consumer Research Volume 18, 1991, Pages 426-431. Association for Consumer Research.

Lexy J. Moleong. 2002. Edisi: Cet.ke-16. Metodologi Kajian Kualitatif. Penerbit Remaja Rosdakarya. Bandung
Pusat Studi Transportasi dan Logistik (PUSTRAL) Universitas Gadjah Mada (UGM). 2013. Laporan Kajian dan Pemilihan Proyek Kerjasama Pemerintah dan Swasta dalam Pengembangan Infrastruktur Transportasi Kawasan Malioboro. Kerjasama dengan BAPPEDA Kota Yogyakarta dan Komite Kebijakan Percepatan Pembangunan Infrastruktur (KKPPI). Yogyakarta.

Andi Mappi Sammeng. 2001. Cakrawala Pariwisata. Balai Pustaka. Jakarta.

Sriti Mayang Sari. 2010. Sejarah Evolusi Shopping Mall. Jurnal DIMENSI INTERIOR, VOL. 8, No. 1, Juni 2010: 52-62.

Arif B Sholihah. 2005. The Role of Informal Street Activities in the Context of Conserving Urban Cultural Entity. Master Thesis. Faculty of Built Environment, Universiti Teknologi Malaysia.

Singapore Tourism Board. 2017. Year-inReview 2016. 14 Februari 2017. Singapore.

Snepenger, David J., Leann Murphy, RyanO'Connell, dan EricGregg. 2003. Tourists and residents use of a shopping space. Annals of Tourism Research Journal, Volume 30, Issue 3, July 2003 Pages 567-580. Elsevier Publisher.

Muhammad Ainul Yaqin, Setijanti Purwanita. 2017. Increasing Customer Intention to Visit Mall in Surabaya- An Architectural Perspective. The International Union of Architects (UIA) 2017 Seoul World Architects Congress Proceedings and Academic Paper INERSIA, Vol. XIV No. 1, Mei 2018 
Status dan Peran ... (Muhammad/ hal. 75-89)

Session Programme. Seoul, Korea.

Oka A Yoeti. 1983. Pengantar IImu Pariwisata. Penerbit Angkasa. Bandung.

Oka A Yoeti. 2008. Ekonomi Pariwisata: introduksi, informasi, dan aplikasi. Penerbit Buku Kompas, Jakarta. 